\title{
Lithocholic Acid Derivative as a Model for Artificial Receptors: A Raman Study
}

\author{
F.M.F. Roleira*,1, E.J. Tavares da Silva ${ }^{1}$, Rui A. Carvalho ${ }^{2}$ and M.P.M. Marques ${ }^{*, 3,4}$ \\ ${ }^{I}$ CEF - Laboratory of Pharmaceutical Chemistry, Faculty of Pharmacy, University of Coimbra, Portugal \\ ${ }^{2}$ CNC - Department of Life Sciences, Faculty of Science and Technology, University of Coimbra, Portugal \\ 3 “Molecular Physical-Chemistry”, University of Coimbra, Portugal \\ ${ }^{4}$ Department of Life Sciences, Faculty of Science and Technology, University of Coimbra, Portugal \\ Received March 08, 2010: Revised May 14, 2010: Accepted June 01, 2010
}

\begin{abstract}
Two lithocholic acid (LCA) derivatives - mono- and diesters (newly synthetised) - are studied for their main conformational preferences, by Raman spectroscopy coupled to theoretical (DFT) methods. Raman bands characteristic of each compound were assigned, allowing an accurate and rapid identification of this kind of systems. The conformational preferences of the LCA diester were related with its ability to function as a model for artificial receptors, displaying a tailored structural profile.
\end{abstract}

Keywords: Lithocholic acid derivatives, Artificial receptors, Conformational analysis, Raman spectroscopy.

\section{INTRODUCTION}

Bile acids are polyhydroxylated steroidal acids present in the digestive systems of vertebrates [1]. They are the final products of the metabolism of cholesterol, and are essential for the solubilisation and transport of dietary lipids. The primary bile acids formed in the liver, and the most abundant in mammals are hydroxy derivatives of cholanoic acid such as cholic $(3 \alpha, 7 \alpha, 12 \alpha$-trihydroxy-5 $\beta$-cholanic acid, CA) and chenodeoxycholic $(3 \alpha, 7 \alpha$-dihydroxy-5 $\beta$-cholanic acid) acids. Lithocholic acid ( $3 \alpha$-hydroxy- $5 \beta$-cholanic acid, LCA), in turn, is a lipid-soluble monohydroxy secondary bile acid, formed by bacterial 7-dehydroxylation of a primary bile acid.

Cholic acid analogues display a variety of biological functions: they may have antiviral and antifungal properties, and can act as sialyltransferase inhibitors [2] or even assist transport of anticancer agents (eg. cisplatin [3]). Moreover, combinations of bile acids and drugs were found to lead to liver-specific pharmaceuticals or to cholesterol-lowering agents, as well as to improve the resorption of poorly absorbable drugs. Lithocholic acid derivatives, in particular, have been reported to act as Vitamin D receptor (VDR) modulators [4], and as selective DNA-polymerase inhibitors [5-7].

Another interesting application of bile acids lies in the field of Supramolecular Chemistry. In fact, molecular recognition and artificial receptors (AR's) have been actual matters of interest in Medicinal Chemistry and Pharmacology. Mostly, the design and the synthesis of artificial

*Address correspondence to these authors at the CEF - Lab. Pharmaceutical Chemistry, Fac. Pharmacy, University of Coimbra, 3000-548 Coimbra, Portugal; Tel: +351 239488 400; Fax: +351 239488 503;

E-mail: froleira@ff.uc.pt

Dep. Life Sciences, Fac. Science and Technology, University of Coimbra, Ap. 3046, 3001-401 Coimbra, Portugal; Tel: +351 239 826541;

Fax: +351 239 826541; E-mail: pmc@ci.uc.pt receptors (AR's) capable of recognising specific substrates, have been taken up [8] in order to improve their stability, transport and bioavailability. Bile acid-based compounds, namely cholic and lithocholic acids, are readily available chiral building blocks for designing novel supramolecular hosts for molecular recognition [9-13]. The design and synthesis of entities displaying a tailored molecular recognition profile (AR's) are accomplished not only by gathering the various required chemical elements, but also by achieving a precise relative spatial disposition of these moieties and a suitable three-dimensional shape of the overall assembly. Hence, there is a tight requirement for molecules with welldefined structures, for which conformational freedom is kept under tight control. An accurate conformational analysis of the AR's and their synthetic intermediates is therefore essential. This may be attained by the use of vibrational spectroscopy (e.g. Raman, which is particularly suitable for the study of systems under physiological conditions), coupled to the theoretical prediction (through quantum mechanical calculations) of their most stable geometries and spectral patterns.

The present work aims to investigate litocholic acid derivatives (Fig. 1) for their conformational requirements, in order to function as suitable models for new AR's. Thus, two compounds - a monoester and a diester of lithocholic acid (Fig. 1) - were designed and synthesised (the latter being a new molecule) and their main conformational preferences were obtained by Raman spectroscopy combined to theoretical calculations - geometry optimisation and calculation of the vibrational spectra. Furthermore, the structure of a possible AR (Fig. 2) was predicted theoretically, in order to aquire knowledge on its three-dimensional shape and relative spatial orientation of its chemical constituents. Finally, the conformational preferences of the litocholic acid esters were compared to those of the proposed AR, particularly regarding the linkage between the steroid moiety of the bile acids and the aromatic structure of the spacer. 


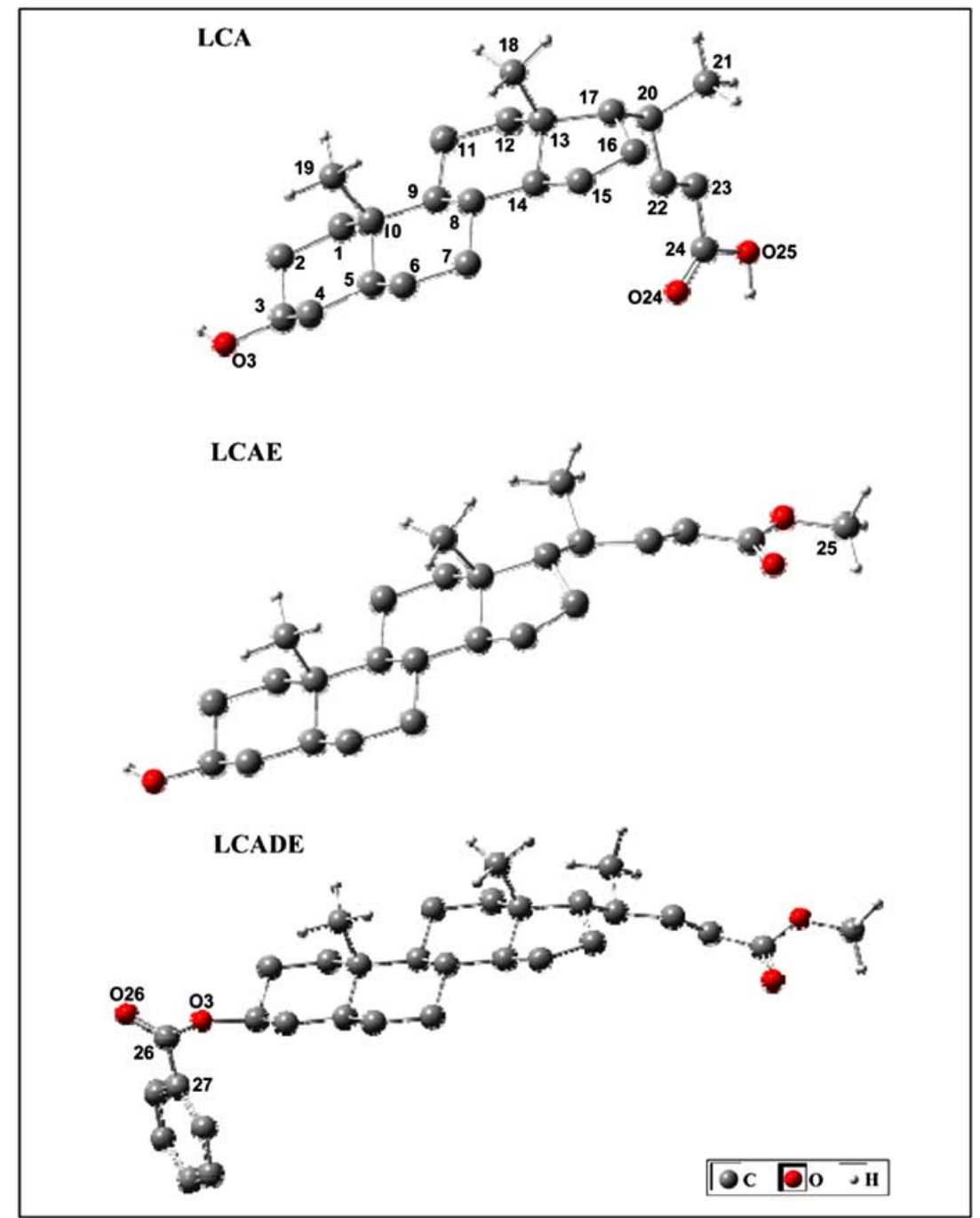

Fig. (1). Schematic representation of the most stable geometries calculated (B3LYP/6-31G*) for the compounds studied in the present work: lithocholic acid (LCA) and their monoester (LCAE) and diester (LCADE) derivatives. (Not all hydrogens atoms are shown, for clarity sake. The atom numbering is included).

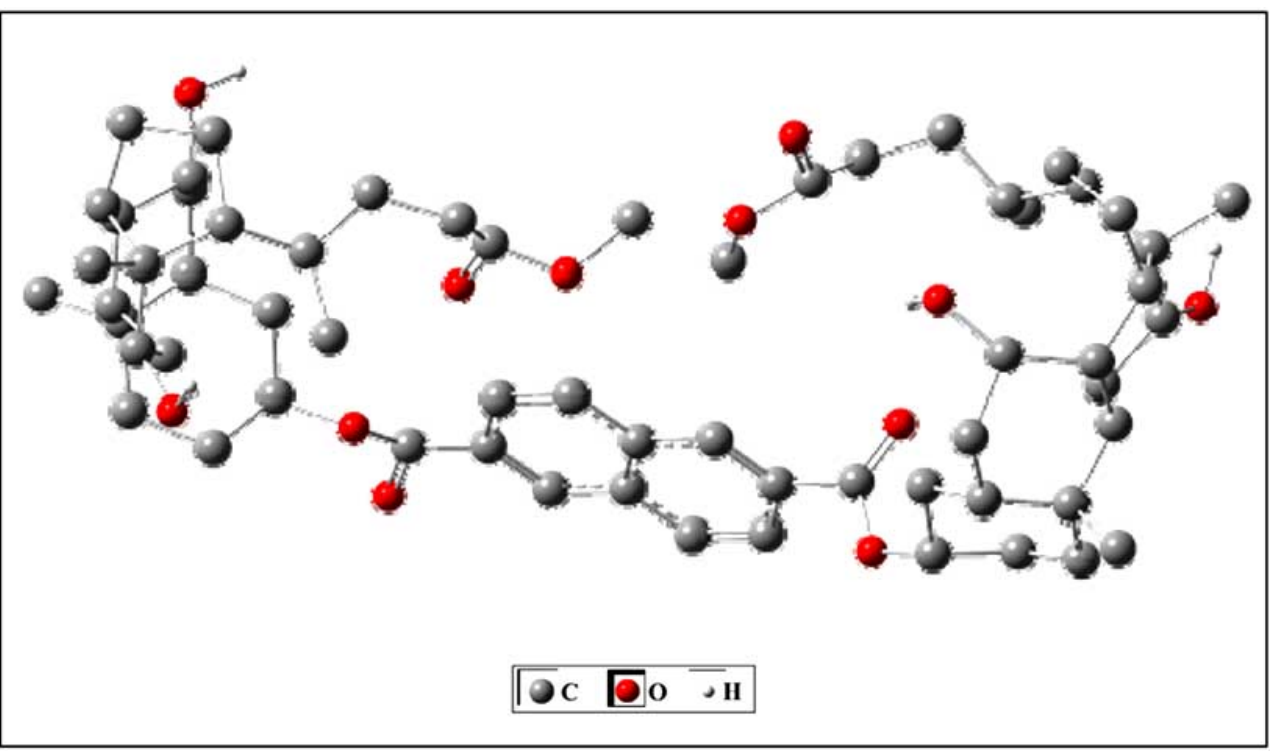

Fig. (2). Schematic representation of the calculated geometry of a possible artificial receptor based on an LCADE analogue. (The calculation was performed considering physiological conditions $-\mathrm{pH} c a$. 7, RT. Not all hydrogens atoms are shown, for clarity sake). 


\section{MATERIALS AND METHODS}

\subsection{Chemicals and Conditions}

Chemicals were purchased from Sigma, Aldrich and Fluka and used as supplied by the manufacturers. Solvents were dried, whenever needed, according to described procedures.

The ${ }^{1} \mathrm{H}$ NMR and ${ }^{13} \mathrm{C}$ NMR spectra were recorded at $599.7 \mathrm{MHz}$ and $150.8 \mathrm{MHz}$, respectively, on a Varian VNMRX spectrometer. Chemical shifts were recorded in $\delta$ values (ppm) downfield from TMS as internal standard. Coupling constants are in $\mathrm{Hz}$.

\subsection{Synthesis and NMR Data}

\section{$3 \alpha$-Hydroxy-5 $\beta$-cholanic acid methyl ester (LCAE)}

Fisher esterification of litocholic acid ( $\boldsymbol{L C A}$ ) with methanol-HCl (5\%), at room temperature, gave the title compound $(\boldsymbol{L C A E})$ in almost quantitative yield (Scheme 1).

${ }^{1} \mathrm{H}$ NMR $\left(\mathrm{CDCl}_{3}\right): \delta 3.65\left(3 \mathrm{H}, s, \mathrm{H}_{3} \mathrm{C}-\mathrm{O}\right), 3.61(1 \mathrm{H}, m$, $\underline{\mathrm{HC}}-3), 0.91\left(3 \mathrm{H}, s, \underline{\mathrm{H}}_{3} \mathrm{C}-18\right), 0.89\left(3 \mathrm{H}, d, J=7.2, \underline{\mathrm{H}}_{3} \mathrm{C}-24\right)$, $0.63\left(3 \mathrm{H}, s, \underline{\mathrm{H}}_{3} \mathrm{C}-19\right)$.

${ }^{13} \mathrm{C}$ NMR $\left(\mathrm{CDCl}_{3}\right): \delta 174.8,71.8,56.4,55.9,51.4,42.7$, $42.1,40.4,40.1,36.4,35.8,35.3$ (2 carbons), 34.5, 31.0, $30.9,30.5,28.2,27.2,26.4,24.2,23.3,20.8,18.2,12.0$.

\section{$3 \alpha$-Benzoyloxy-5 $\beta$-cholanic acid methyl ester (LCADE)}

The methyl ester (LCAE) was esterified at C-3, according to previous descriptions [14], using dicyclohexylcarbodiimide (DCC) as a coupling agent and dimethylaminopyridine (DMAP) in dichloromethane, at room temperature, yielding the diester (LCADE) (Scheme 1).

${ }^{1} \mathrm{H}$ NMR $\left(\mathrm{CDCl}_{3}\right): \delta 8.04(2 \mathrm{H}, d t, J=7.2, J=1.2, \mathrm{H}-$ aro), $7.53(1 \mathrm{H}, t t, J=7.2, J=1.2, \mathrm{H}$-aro $), 7.42(1 \mathrm{H}, t, J=$ 7.2, H-aro), 4.97 (1H, $m, \underline{\mathrm{HC}}-3), 3.66\left(3 \mathrm{H}, s, \underline{\mathrm{H}}_{3} \mathrm{C}-\mathrm{O}\right), 0.96$ $\left(3 \mathrm{H}, s, \underline{\mathrm{H}}_{3} \mathrm{C}-18\right), 0.91\left(3 \mathrm{H}, d, J=6.6, \underline{\mathrm{H}}_{3} \mathrm{C}-24\right), 0.65$ (3H, $s$, $\left.\underline{\mathrm{H}}_{3} \mathrm{C}-19\right)$.
${ }^{13} \mathrm{C} \mathrm{NMR}\left(\mathrm{CDCl}_{3}\right): \delta 174.7,166.1,132.6,130.9,129.5(2$ carbons), 128.2 (2 carbons), 75.0, 56.5, 56.0, 51.5, 42.7, $41.9,40.5,40.1,35.8,35.3,35.1,34.6,32.3,31.0,30.9,28.2$, $27.0,26.7,26.3,24.2,23.3,20.9,18.3,12.0$.

\subsection{Raman Spectroscopy}

The Raman spectra were obtained at room temperature, in a triple monochromator Jobin-Yvon T64000 Raman system (focal distance $0.640 \mathrm{~m}$, aperture $f / 7.5$ ) with holographic gratings of 1800 grooves. $\mathrm{mm}^{-1}$. The premonochromator stage was used in the subtractive mode. The detection system was a liquid nitrogen cooled non-intensified $1024 \times 256$ pixel (1") Charge Coupled Device (CCD). The entrance slit was set to $200 \mu \mathrm{m}$, and the slit between the premonochromator and the spectrograph was opened to $12 \mathrm{~mm}$.

The excitation radiation was provided $(c a .100 \mathrm{~mW}$ at the sample position) by the $514.5 \mathrm{~nm}$ line of an $\mathrm{Ar}^{+}$laser (Coherent, model Innova 300 ). $90^{\circ}$ geometry between the incident radiation and the collecting system was employed. Samples were sealed in Kimax glass capillary tubes of 0.8 $\mathrm{mm}$ inner diameter. Under the above mentioned conditions, the error in wavenumbers was estimated to be within $1 \mathrm{~cm}^{-1}$.

\subsection{Quantum Mechanical Calculations}

The quantum mechanical calculations were performed using the GAUSSIAN 03W program [15], within the Density Functional Theory (DFT) approach, in order to properly account for the electron correlation effects (particularly important in this kind of conjugated system). The widely employed hybrid method denoted by B3LYP, which includes a mixture of HF and DFT exchange terms and the gradientcorrected correlation functional of Lee, Yang and Parr $[16,17]$, as proposed and parametrised by Becke [18,19], was used along with the double-zeta split valence basis set 6$31 \mathrm{G}^{*}[20]$.

Molecular geometries were fully optimised by the Berny algorithm, using redundant internal coordinates [21], the<smiles>CC(=O)CCC(C)[C@H]1CCC2C3CC[C@H]4C[C@H](O)CC[C@]4(C)C3CCC2(C)C1C</smiles><smiles>CC(=O)CCC(C)[C@H]1CCC2C3CC[C@H]4C[C@H](OC(=O)c5ccccc5)CC[C@]4(C)C3CCC21C</smiles>

Scheme 1. 
bond lengths to within $\mathrm{ca} .0 .1 \mathrm{pm}$ and the bond angles to within $c a .0 .1^{\circ}$. The final root-mean-square (rms) gradients were always less than $3 \times 10^{-4}$ hartree bohr $^{-1}$ or hartree $\operatorname{radian}^{-1}$. No geometrical constraints were imposed on the molecules under study. The relative energies and populations (Boltzman distribution at $298.15 \mathrm{~K}$ ) were calculated for all conformers, using the sum of electronic and zero-point energies.

Calculation of the harmonic vibrational wavenumbers was carried out for all conformations (at the B3LYP/6-31G* level of theory [22]), in order to check for minima in the potential energy surface and to obtain the theoretical vibrational pattern (both Raman and infrared) of the compounds. Wavenumbers above $400 \mathrm{~cm}^{-1}$ were scaled by a factor of 0.9614 [23] before comparing them with the experimental data, in order to correct for the anharmonicity of the normal modes of vibration.

\section{RESULTS AND DISCUSSION}

The purpose of the present study is to elucidate the ability of lithocholic acid analogues to function as models for artificial receptors, in the light of their conformational behaviour. Therefore, two LCA ester derivatives - monoester (LCAE) and diester (LCADE) (Fig. 1) were synthesised (Scheme 1) and analysed for their conformational preferences, as compared to those of their precursor lithocholic acid (LCA). Furthermore, an LCADE-based artificial receptor is also proposed (Fig. 2).

A thorough characterisation of the newly prepared lithocholic esters was carried out by vibrational (Raman) spectroscopy. A complete structural identification was achieved by assigning the experimental spectra obtained for the solid samples at room temperature, in the light of the theoretically predicted vibrational results. This procedure, previously used by the authors for performing conformational studies of phenolic systems [24-31], will allow to obtain the preferred conformation of each investigated compound (i.e. its most stable form at room temperature).

Three distinct conformers were found for lithocholic acid (Fig. 3), differing in the orientation of the pendant arm at position 17 relative to the condensed ring structure (Fig. 1) either folded $\left(\mathrm{C}^{13} \mathrm{C}^{17} \mathrm{C}^{20} \mathrm{C}^{22}=-69^{\circ}\right)$ or stretched $\left(\mathrm{C}^{13} \mathrm{C}^{17} \mathrm{C}^{20} \mathrm{C}^{22}\right.$

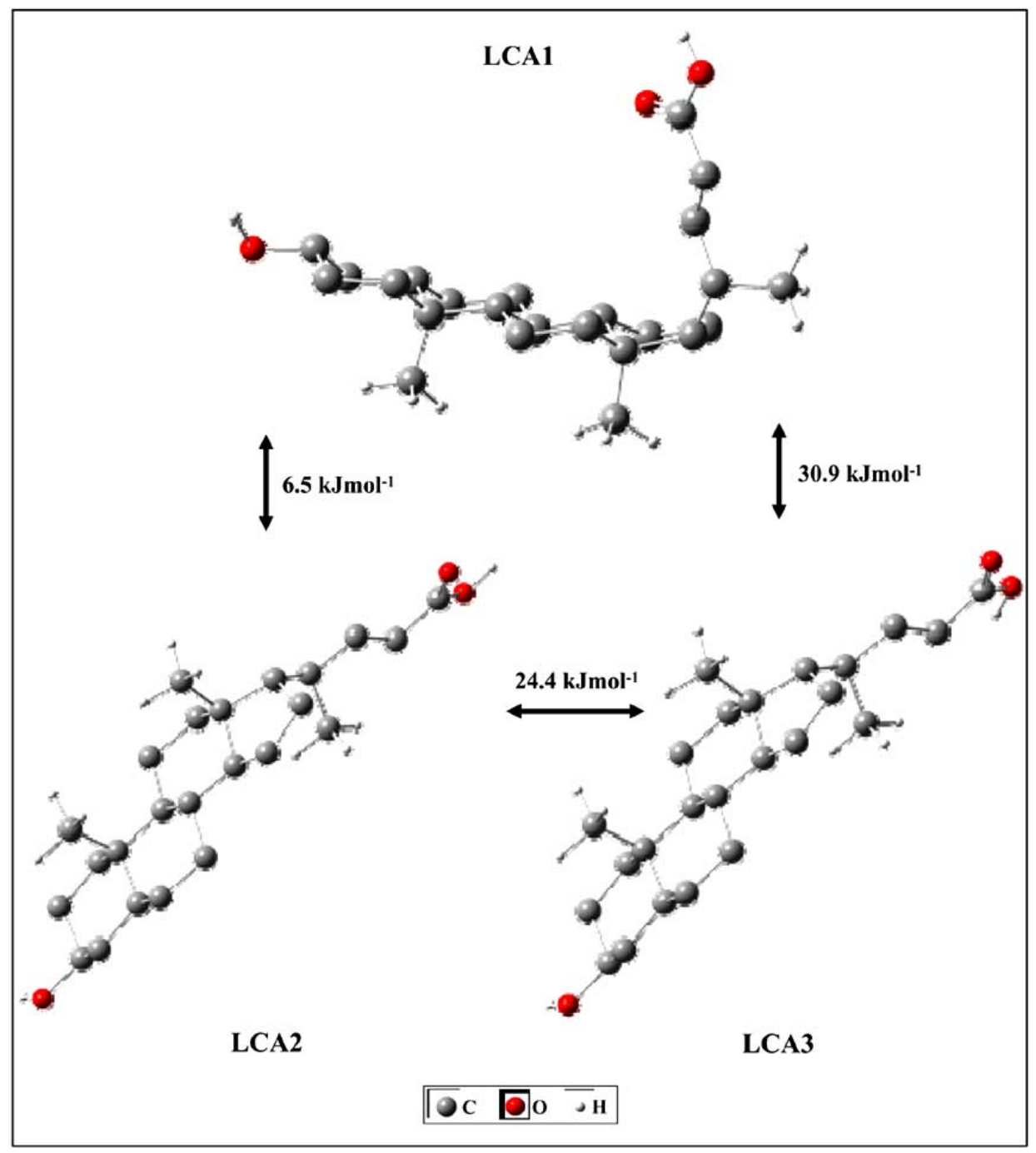

Fig. (3). Schematic representation of the calculated conformers (B3LYP/6-31G*) obtained for lithocholic acid (LCA). (Not all hydrogens atoms are shown, for clarity sake). 
$\left.=-163^{\circ}\right)-$ and in the conformation of the carboxylic moiety either S-cis $\left(\mathrm{HO}^{25} \mathrm{C}^{24}=\mathrm{O}^{24}=0^{\circ}\right)$ or S-trans $\left(\mathrm{HO}^{25} \mathrm{C}^{24}=\mathrm{O}^{24}=\right.$ $\left.180^{\circ}\right)$. The most stable species for the isolated molecule (LCA1) was found to be the gauche one displaying an S-cis geometry (in accordance with previous reported studies on several phenolic carboxylic systems [29,32-34]). Among the quasi-trans geometries (LCA2 and LCA3), the S-cis one (LCA2) is favoured relative to the S-trans (LCA3) by 24.4 $\mathrm{kJ} \mathrm{mol}^{-1}$, and is also the predominant one in the condensed phase (in agreement with the reported X-ray structure for lithocholic acid [35], Table 1S, Supplementary Material). For the monoester (LCAE) and the diester (LCADE) derivatives, in turn, only one stable conformation was yielded by the calculations (Fig. 1).

Coupling the theoretical results to the Raman data presently obtained enables to thoroughly elucidate the detailed geometry of the newly synthesised LCA esters. Special attention was paid to the conformational preferences of the substituent groups in positions 3 and 17 of the parent acid molecule (Fig. 1), which are directly related to those that are the most demanding positions in cholic acid-based ARs.

While both the gauche (LCA1, $\mathrm{C}^{13} \mathrm{C}^{17} \mathrm{C}^{20} \mathrm{C}^{22}=-69^{\circ}$ ) and trans (LCA2, LCA3) conformations are possible for lithocholic acid, esterification at the carboxylic terminal was found to lead to an overall conformational rearrangement of the molecule, from a tilted to an extended (trans) geometry: $\mathrm{C}^{13} \mathrm{C}^{17} \mathrm{C}^{20} \mathrm{C}^{22}$ equal to $-163^{\circ}$ for the monoester, and to $-169^{\circ}$ for the diester (Fig. 1, Table 1S). In addition, whereas the methoxy and the carbonyl groups are almost coplanar, the whole ester moiety is tilted relative to the molecule $-\theta=15$ $16^{\circ}$ in both LCAE and LCADE (Fig. 1S, Supplemmentary Material). In the latter, the benzoyloxy substituent in position 3 is perpendicular relative to the rest of the molecule $\left(\mathrm{C}^{27} \mathrm{C}^{26} \mathrm{O}^{3} \mathrm{C}^{3}=90^{\circ}\right)$. This is precisely the required geometry for cholic acid-based ARs, in order to achieve molecular clefts capable of recognising specific substrates (see Fig. 2). Therefore, it seems reasonable to state that the ester function is a convenient linkage between the steroid moiety and the aromatic spacer in the presently proposed ARs.

The spectroscopic data currently obtained for lithocholic acid is in accordance with previous reported results [36]. Moreover, several characteristic vibrational features are evidenced for the two synthesised esters (Figs. 4 and 5; Table 2S, Supplementary Material), that allow their ready differentiation and identification, corroborating Raman spectroscopy as a rapid and reliable technique for the analysis of these kind of samples. Apart from the typical vibrational modes of these lithocholic-based systems - CC stretchings (below $750 \mathrm{~cm}^{-1}$ ), and $\mathrm{CH}$ stretchings (yielding intense bands centered at ca. $2900 \mathrm{~cm}^{-1}$ ) and deformations (between 900 and $1450 \mathrm{~cm}^{-1}$ ) - the chief distinctive features assigned to the compounds under study are due to the vibrational modes of their main functional groups (Table $\mathbf{2 S}$ ):

$\mathrm{OH}$ - stretchings, predicted at about $3333 \mathrm{~cm}^{-1}$ but hardly detected experimentally (very weak and broad bands above $3300 \mathrm{~cm}^{-1}$ ); bendings, around $1044 \mathrm{~cm}^{-1}$ (in agreement with an equatorial orientation of the ring ${ }^{3} \mathrm{OH}$ group), and out-of-plane deformations, from 300 to $650 \mathrm{~cm}^{-1}$. These bands are absent in the diester (which does not comprise $\mathrm{OH}$ groups). (ii) $\mathrm{C}=\mathrm{O}-$ stretching, between 1700 and $1740 \mathrm{~cm}^{-1}$. In the acid, a red shift is detected relative to the calculated value $\left(1702\right.$ vs $\left.1711 \mathrm{~cm}^{-1}\right)$, due to the occurrence of $\mathrm{H}$-bond type intermolecular interactions in the condensed phase (which are not considered in the theoretical model). The inductive effect of the alkyl $\left(\mathrm{CH}_{3}\right)$ group, in the esters, raises the frequency of the $v_{\mathrm{C}=\mathrm{O}}$ mode (1731 and $\left.1742 \mathrm{~cm}^{-1}\right)$, since it leads to a higher force constant of the $\mathrm{C}=\mathrm{O}$ oscillator. The benzoyloxy group has a similar effect on the nearby carbonyl stretching $\left(1714 \mathrm{~cm}^{-1}\right)$. The deviation to higher frequencies observed in the experimental wavenumbers as compared to the predicted ones for the esters ( $c a$. 1690 vs 1714, 1731 and $1742 \mathrm{~cm}^{-1}$ ), can be explained by the formation of intramolecular close contacts (causing a decrease of the $\mathrm{v}_{\mathrm{C}=\mathrm{O}}$ wavenumber) $-{ }^{24} \mathrm{O} \cdots$ $\mathrm{HC}^{25}$ (266 pm), and ${ }^{26} \mathrm{O} \cdots \mathrm{HC}^{2}$ (260 pm, in LCADE), that are not favoured in the solid.

(iii) $\left(\mathrm{CH}_{3}\right)_{\text {alkyl }}$ - deformations, asymetric modes from 1470 to $1500 \mathrm{~cm}^{-1}$, and the symmetric one (umbrella mode) at $c a .1420 \mathrm{~cm}^{-1}$, rocking, at ca. 940 to $950 \mathrm{~cm}^{-1}$, and torsion (yielding very low Raman intensity bands), at ca. $216 \mathrm{~cm}^{-1}$ for LCA, $208 \mathrm{~cm}^{-1}$ for LCAE and 230 $\mathrm{cm}^{-1}$ for LCADE.

(iv) $\left(\mathrm{CH}_{3}\right)_{\text {ester }}$ - deformations, at ca. 1470 (asymmetric) and $1423 \mathrm{~cm}^{-1}$ (umbrella); and rocking, at ca. 1120 $\mathrm{cm}^{-1}$.

(v) Ester moieties (LCAE and LCADE) - C-O stretching modes, at $941 \mathrm{~cm}^{-1}$ for $\mathrm{LCAE}\left(\mathrm{C}-\mathrm{OCH}_{3}\right)$, and 946 and $1233 \mathrm{~cm}^{-1}$ for LCADE $((\mathrm{O}=\mathrm{C}) \mathrm{C}-\mathrm{O})$ (as compared to the value for LCA $\left.\left(\mathrm{v}_{\mathrm{C}-\mathrm{O}(\mathrm{H})}=1026 \mathrm{~cm}^{-1}\right)\right)$. Chain deformations, both in-plane $\left(\Delta_{\mathrm{O}-\mathrm{C}-\mathrm{O}}\right)$ and out-of-plane $\left(\Gamma_{\text {O-C-O }}\right)$, detected for both esters as quite intense and well-defined bands between 600 to $800 \mathrm{~cm}^{-1}$; and O$\mathrm{CH}_{3}$ rotation, yielding a low frequency band, at 73 $\mathrm{cm}^{-1}$ for LCAE and $88 \mathrm{~cm}^{-1}$ for LCADE.

(vi) Aromatic ring (LCADE) - stretching modes, giving rise to intense bands at $1005 \mathrm{~cm}^{-1}$ (ring breathing, most intense feature of the spectrum), $1586 \mathrm{~cm}^{-1}$ (weak feature) and $1605 \mathrm{~cm}^{-1}$; C-H deformations, at $1454 \mathrm{~cm}^{-1}$ (in-plane) and $845 \mathrm{~cm}^{-1}$ (out-of-plane).

As expected, the diester displays two $v_{\mathrm{C}=\mathrm{O}}$ modes (at 1714 and $1742 \mathrm{~cm}^{-1}$ ), which allow its prompt identification when compared to the monoester $\left(v_{\mathrm{C}=\mathrm{O}}=1731 \mathrm{~cm}^{-1}\right)$ and the acid $\left(v_{\mathrm{C}=\mathrm{O}}=1702 \mathrm{~cm}^{-1}\right)$ (Fig. 4). Moreover, LCADE yields intense Raman features due to ring $\mathrm{CC}$ stretching vibrations at 1005 and $1605 \mathrm{~cm}^{-1}$, out-of-plane $(\mathrm{C}-\mathrm{H})_{\text {ring }}$ bending modes at $845 \mathrm{~cm}^{-1}$ (Fig. 4), and ring $\mathrm{C}-\mathrm{H}$ stretching from 3054 to $3073 \mathrm{~cm}^{-1}$ (Fig. 5). The monoester, in turn, is easily distinguished from the parent acid, mainly through the higher wavenumber of the $v_{\mathrm{C}=\mathrm{O}}$ feature $\left(1731\right.$ vs $\left.1702 \mathrm{~cm}^{-1}\right)$ and from the $\Delta_{\text {O-C-O }}$ band at $619 \mathrm{~cm}^{-1}$ (Fig. 4).

A comparison between the experimental and calculated Raman frequencies evidences a quite good overall agreement (Table 2S, Figs. 4 and 5), although the calculations were performed for the isolated molecules. Actually, discrepancies between experimental and theoretical wavenumbers are expected only upon the formation of intermolecular hydrogen bonds (not considered in the theoretical approach currently used) that will affect the vibrational modes associated to the 
groups involved. In the compounds presently studied, top-totop H-bond intermolecular interactions are prone to occur only in the acid, between the terminal carboxylic and hydroxyl $\left({ }^{3} \mathrm{OH}\right.$, Fig. 1) functions $(\mathrm{O}-\mathrm{H} \cdots \mathrm{O}$ distances equal to ca. $260 \mathrm{pm}$ ), yielding dimeric entities (which, according to $\mathrm{X}$-ray results, are repeated periodically in the solid [35]). These intermolecular interactions are reflected in the very broad, almost undetectable $\mathrm{v}_{\mathrm{O}-\mathrm{H}}$ features, which correspond to an alcohol bonded $\mathrm{OH}$ (at $3380 \mathrm{~cm}^{-1}$ ) and an acid bonded hydroxyl (at $3300 \mathrm{~cm}^{-1}$ ), as well as in the broadness of the ${ }^{3} \mathrm{OH}$ bending band (around $1040 \mathrm{~cm}^{-1}$ ). They are also responsible for the low frequency shift observed for the $v_{C=O}$ Raman experimental value $\left(1702 \mathrm{~cm}^{-1}\right)$ relative to the predicted one $\left(1711 \mathrm{~cm}^{-1}\right)$, in accordance with the expected weakening of the $\mathrm{C}=\mathrm{O}$ oscillator upon hydrogen-bond formation. This polymeric association in LCA, in the solid state, through $\mathrm{O}-\mathrm{H}{ }^{\cdots} \mathrm{O}$ intermolecular interactions between the ${ }^{3} \mathrm{OH}$ and $\mathrm{C}=\mathrm{O}$ groups of adjacent molecules, can explain the strong hydrophobic character and low water solubility of this compound [37]. In fact, the vibrational data reported for LCA in $\mathrm{CHCl}_{3}$ solution [36] clearly reflected the presence of both the dimeric and monomeric species, yielding well defined $\mathrm{OH}$ stretching features corresponding to the latter (at 3690 (alcohol) and $3608 \mathrm{~cm}^{-1}$ (acid)) as compared to the bound broad $v_{\mathrm{OH}}$ mode signal at $3059 \mathrm{~cm}^{-1}$, and a free $v_{\mathrm{C}=\mathrm{O}}$ band at $1741 \mathrm{~cm}^{-1}$ in contrast to the free carbonyl stretching at $1702 \mathrm{~cm}^{-1}$ (Table 2S). Furthermore, the relationship between the bands corresponding to the free and bound acid molecules was found to be unaffected by dilution, which implies that only a small portion of intermolecular H-bonds are broken by solvent effects, the major solid state structure remaining the one reported for the crystalline lattice [35].

For the esters, in turn, this kind of dimers cannot be formed and the only possible dimeric entities in the solid phase would rely on the occurrence of $\mathrm{O}{ }^{\cdots} \mathrm{H}$ close contacts involving the carbonyl, the ring hydroxyl and/or the methoxy groups, yielding layered dimeric entities in the solid phase $[33,38]$. However, these are not favoured by the overall structure of the molecules that will lead to strong steric repulsions upon approach, thus hindering the occurrence of stable dimers.

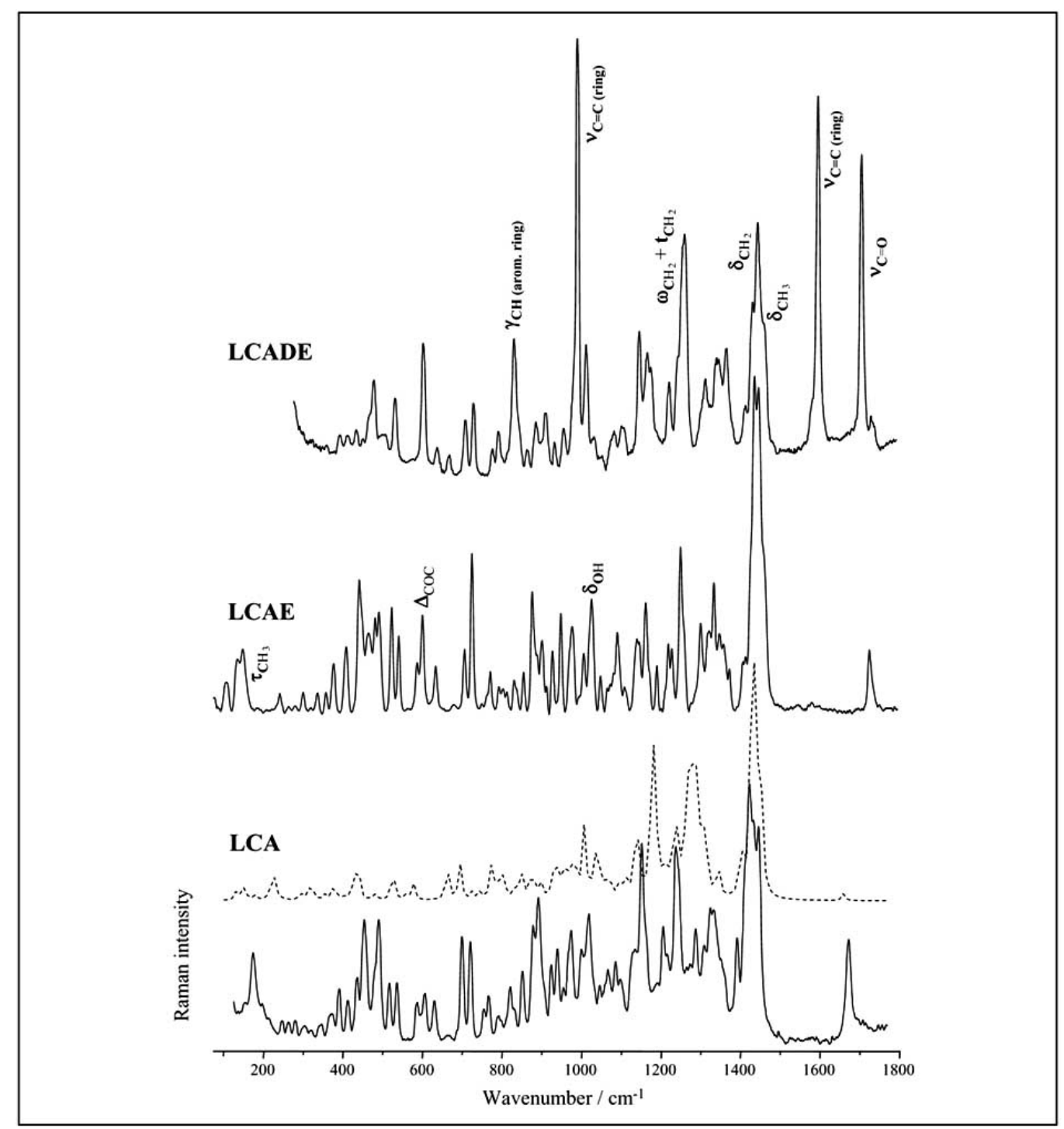

Fig. (4). Raman spectra $\left(100-1800 \mathrm{~cm}^{-1}\right.$, solid state at $\left.25^{\circ} \mathrm{C}\right)$ for lithocholic acid (LCA) and their monoester (LCAE) and diester (LCADE) derivatives. (Dotted line - calculated (B3LYP/6-31G*) Raman spectrum for LCA). 


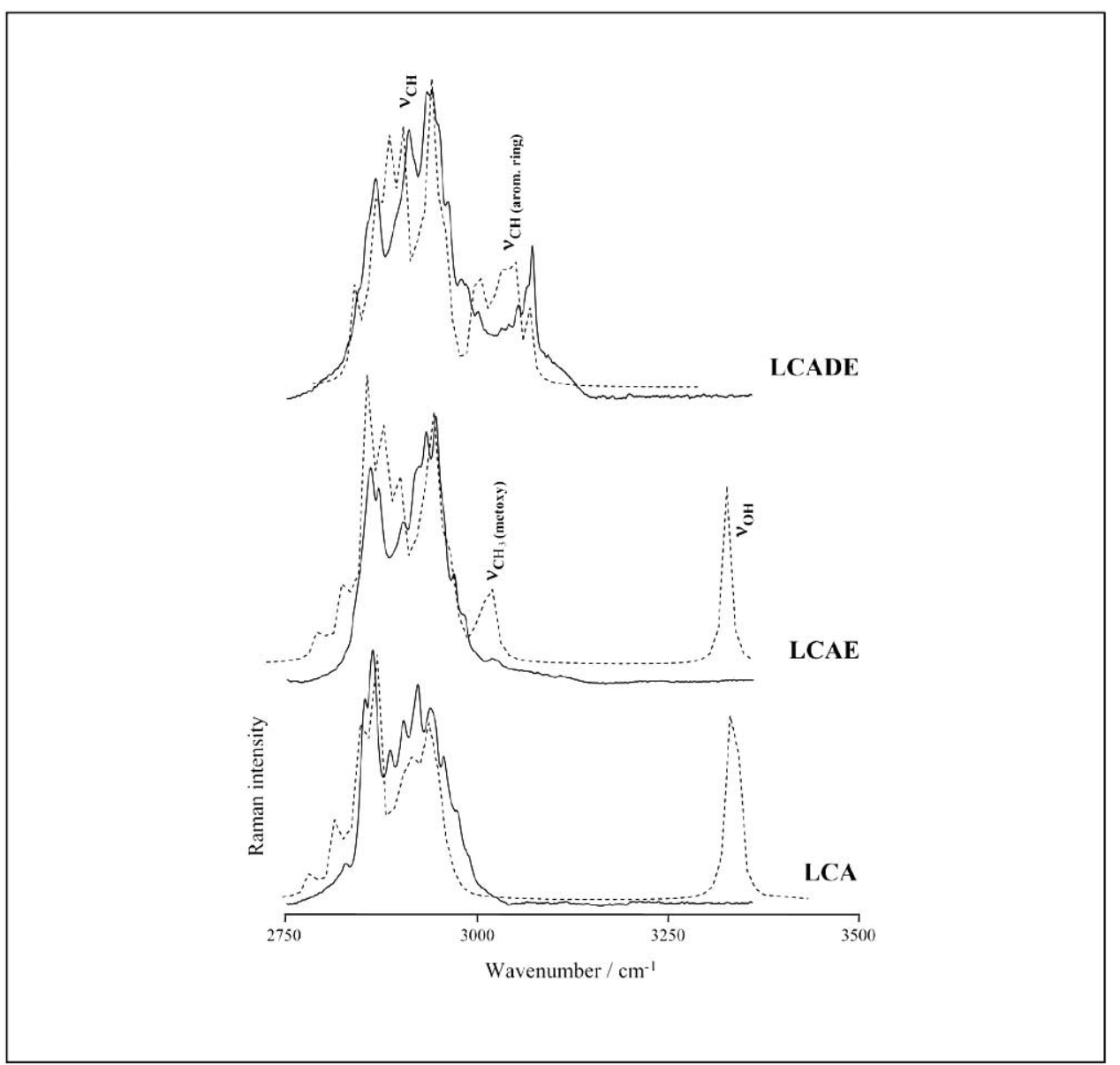

Fig. (5). Raman spectra $\left(2500-3800 \mathrm{~cm}^{-1}\right.$, solid state at $\left.25{ }^{\circ} \mathrm{C}\right)$ for lithocholic acid (LCA) and their monoester (LCAE) and diester (LCADE) derivatives. (Dotted lines - calculated (B3LYP/6-31G*) Raman spectra).

\section{CONCLUSIONS}

The synthesis and Raman characterisation of cholic and lithocholic acid-based molecules, aimed as models for novel supramolecular hosts, was carried out.

Typical Raman features were obtained for each of the three compounds studied - the parent acid, the mono- and the diester - leading to an accurate characterisation of each derivative. The structural analysis presently carried out allowed to attain a precise knowledge of the conformational behaviour of the molecules investigated, particularly as regards to the LCA substituents in positions 3 and 17. As to LCADE, the benzoyloxy group in position 3 assumes a perpendicular geometry relative to the steroid moiety, which prompts us to state that the ester function may be suitable for linking the aromatic spacer to the steroid moiety in the AR, allowing to propose LCADE as a good model for cholic acid-based receptors.

Additionally, the Raman spectroscopic analysis performed for LCA and its esters yields a library of data which will enable a quick, inexpensive and unequivocal identification of these kind of compounds in the future. Actually, due to its non-invasiveness, high sensitivity and good reproducibility, apart from the fact that it needs virtually no sample preparation, Raman spectroscopy is presently becoming an important tool in the Medicinal Chemistry and Forensic Sci- ences, as a simple and reliable method for the screening and identification of unknown samples, once it yields unique fingerprint spectra, specific for each compound.

\section{ACKNOWLEDGEMENT}

To FCT (Fundação para a Ciência e Tecnologia), Portugal, for financial support.

\section{SUPPLEMENTARY MATERIAL}

Supplementary material is available on the publishers Web site along with the published article.

\section{REFERENCES}

[1] Kritchevsky, D.; Nair, P.P. The Bile Acids: Chemistry, Physiology, and Metabolism, Vol. 1, Kritchevsky D. Eds., Plenum: New York, 1971.

[2] Chang, K.H.; Lee, L.; Chena, J.; Li, W.S. Lithocholic acid analogues, new and potent alpha-2,3-sialyltransferase inhibitors. Chem. Commun., 2006, 629-631.

[3] Paschke, R.; Kalbitz, J.; Paetz, C. Novel spacer linked bile acidcisplatin compounds as a model for specific drug delivery, synthesis and characterization. Inorg. Chim. Acta, 2000, 304, 241-249.

[4] Ishizawa, M.; Matsunawa, M.; Adachi, R.; Uno, S.; Ikeda, K. Masuno, H.; Shimizu, M.; Iwasaki, K.; Yamada, S.; Makishima, M. Lithocholic acid derivatives act as selective vitamin D receptor 
modulators without inducing hypercalcemia. J. Lipid Res., 2008, 49, 763-772.

[5] Mizushina, Y.; Kasai, N.; Sugawara, F.; Iida, A.; Yoshida, H.; Sakaguchi, K. Three-dimensional structural model analysis of the binding site of lithocholic acid, an inhibitor of dna polymerase $\beta$ and dna topoisomerase II. J. Biochem., 2001, 130, 657-664.

[6] Nakamura, R.; Takeuchi, R.; Kuramochi, K.; Mizushina, Y.; Ishimaru, C.; Takakusagi, Y.; Takemura, M.; Kobayashi, S.; Yoshida, H.; Sugawara, F.; Sakaguchi, K. Chemical properties of fatty acid derivatives as inhibitors of dna polymerases. Org. Biomol. Chem., 2007, 5, 3912-3921.

[7] Sakaguchi, K.; Sugawara, F. New cancer chemotherapy agents: inhibitors of dna polymerase. Curr. Drug Therapy, 2008, 3, 44-53.

[8] Hartley, J.H.; James, T.D.; Ward, C.J. Synthetic Receptors. J. Chem. Soc. Perkin Trans. 1, 2000, 3155-3184.

[9] Bonar-Law, R.P.; Sanders, J.K.M. Cyclocholates: synthesis and ion binding. Tetrahedron Lett., 1992, 33, 2071-2074 and refs. therein.

[10] Davis, A.P.; Wareham, R.S. Carbohydrate recognition through noncovalent interactions: a challenge for biomimetic and supramolecular chemistry. Angew. Chem. Int. Ed. Engl., 1999, 38, 2978- 2996.

[11] Tamminen, J.; Kolehmainen, E. Bile acids as building blocks of supramolecular hosts. Molecules, 2001, 6, 21-46.

[12] Joachimiak, R.; Paryzek, Z. Synthesis and alkaline metal ion binding ability of new steroid dimers derived from cholic and lithocholic acids. J. Inclusion Phenomena Macrocyclic Chem., 2004, 49, 127-132.

[13] Kim, K.S.; Cho, N.J.; Kim, H.S. Synthesis and anion binding affinities of novel molecular tweezers based on chenodeoxycholic acid bearing different lengths of arm. Bull. Korean Chem. Soc., 2006, 27, 739-743.

[14] Mehta, G.; Muthusamy, S.; Maiya, B.; Arounaguiri, S. Cholateinterspersed porphyrin-anthraquinone conjugates: photonuclease activity of large sized, "tweezer-like" molecules. J. Chem. Soc. Perkin Trans. 1, 1999, 2177-2182.

[15] Frisch, M.J.; Trucks, G.W.; Schlegel, H.B.; Scuseria, G.E.; Robb, M.A.; Cheeseman, J.R.; Zakrzewski, V.G.; Montgomery, J.A. Jr.; Stratmann, R.E.; Burant, J.C.; Dapprich, S.; Millam, J.M.; Daniels, A.D.; Kudin, K.N.; Strain, M.C.; Farkas, O.; Tomasi, J.; Barone, V.; Cossi, M.; Cammi, R.; Mennucci, B.; Pomelli, C.; Adamo, C.; Clifford, S.; Ochterski, J.; Petersson, G.A.; Ayala, P.Y.; Cui, Q.; Morokuma, K.; Malick, D.K.; Rabuck, A.D.; Raghavachari, K.; Foresman, J.B.; Cioslowski, J.; Ortiz, J.V.; Baboul, A.G.; Stefanov, B.B.; Liu, G.; Liashenko, A.; Piskorz, P.; Komaromi, I.; Gomperts, R.; Martin, R.L.; Fox, D.J.; Keith, T.; Al-Laham, M.A.; Peng, C.Y.; Nanayakkara, A.; Challacombe, M.; Gill, P.M.W.; Johnson, B.; Chen, W.; Wong, M.W.; Andres, J.L.; Gonzalez, C.; HeadGordon, M.; Replogle, E.S.; Pople, J.A. Gaussian 03, Revision B.04, Gaussian Inc.: Pittsburgh PA, USA, 2003.

[16] Lee, C.; Yang, W.; Parr, R.G. Development of the colle-salvetti correlation-energy formula into a functional of the electron density. Phys. Rev., 1988, B37, 785-789.

[17] Miehlich, B.; Savin, A.; Stoll, H.; Preuss, H. Results obtained with the correlation energy density functionals of becke and lee, yang and parr. Chem. Phys. Lett., 1989, 157, 200-206.

[18] Becke, A.J. Density-functional exchange-energy approximation with correct asymptotic behavior. Phys. Rev., 1988, A38, 30983100 .

[19] Becke, A.J. Density-functional thermochemistry. iii. the role of exact exchange. J. Chem. Phys., 1993, 98, 5648-5652.

[20] Petersson, G.A.; Bennett, A.; Tensfeldt, T.G.; Al-Laham, M.A.; Shirley, W.A.; Mantzaris, J. A complete basis set model chemistry. $i$ the total energies of closed-shell atoms and hydrides of the firstrow elements. J. Chem. Phys., 1988, 89, 2193-2218.
[21] Peng, C.; Ayala, P.Y.; Schlegel, H.B.; Frisch, M.J. Using redundant internal coordinates to optimize equilibrium geometries and transition states. J. Comp. Chem., 1996, 17, 49-56.

[22] Hariharan, P.C.; Pople, J.A. The influence of polarization functions on molecular orbital hydrogenation energies. Theor. Chim. Acta, 1973, 28, 213-222.

[23] Scott, A.P.; Radom, L. Harmonic vibrational frequencies: an evaluation of hartree-fock, møller-plesset, quadratic configuration interaction, density functional theory, and semiempirical scale factors. J. Phys. Chem., 1996, 100, 16502-16513.

[24] Batista de Carvalho, L.A.E.; Marques, M.P.M.; Tomkinson, J. Drug-excipient interactions in ketoprofen - a vibrational spectroscopy study. Biopolymers, 2006, 82, 420-424.

[25] Marques, M.P.M.; Batista de Carvalho, L.A.E. Vibrational spectroscopy studies on linear polyamines. Biochem. Soc. Trans., 2007, 35, 374-380.

[26] Amado, A.M.; Fiuza, S.M.; Marques, M.P.M.; Batista de Carvalho, L.A.E. Conformational and vibrational study of cisdiamminedichloroplatinum (ii) - all-electron calculations. J. Chem. Phys., 2007, 127, 185104-185110.

[27] Garrido, J.M.P.J.; Marques, M.P.M.; Silva, A.M.S.; Macedo, T.R.A.; Oliveira-Brett, A.M.; Borges, F. Spectroscopic and electrochemical studies of cocaine-opioid interactions. Anal. Bioanal. Chem., 2007, 388, 11799-11808.

[28] Milhazes, N.; Martins, P.; Uriarte, E.; Garrido, J.; Calheiros, R.; Marques, M.P.M.; Borges, F. Electrochemical and spectroscopic characterisation of amphetamine-like drugs: application to the screening of 3,4-methylenedioxymethamphetamine (mdma) and its synthetic precursors. Anal. Chim. Acta, 2007, 596, 231-241.

[29] Calheiros, R.; Machado, N.F.L.; Fiuza, S.M.; Gaspar, A.; Garrido, J.; Milhazes, N.; Borges, F.; Marques, M.P.M. Antioxidant phenolic esters with potential anticancer activity: a raman spectroscopy study. J. Raman Spec., 2008, 39, 95-107.

[30] Machado, N.F.L.; Calheiros, R.; Gaspar, A.; Garrido, J.; Borges, F.; Marques, M.P.M. Antioxidant phenolic esters with potential anticancer activity: solution equilibria studied by raman spectroscopy. J. Raman Spec., 2009, 40, 80-85.

[31] Milhazes, N.; Borges, F.; Calheiros, R.; Marques, M.P.M. Identification of synthetic precursors of amphetamine-like drugs using raman spectroscopy and ab initio calculations: $\beta$-methyl- $\beta$ nitrostyrene derivatives. Analyst, 2004, 129, 1106-1117.

[32] Van Besien, E.; Marques, M.P.M. Ab Initio conformational study of caffeic acid. J. Mol. Struct. (THEOCHEM), 2003, 625, 265-275.

[33] Fiuza, S.M.; Van Besien, E.; Milhazes, N.; Borges, F.; Marques, M.P.M. Conformational analysis of a trihydroxylated derivative of cinnamic acid - a combined raman spectroscopy and ab initio study. J. Mol. Struct., 2004, 693, 103-118.

[34] Machado, N.F.L.; Calheiros, R.; Fiuza, S.M.; Borges, F.; Gaspar, A.; Garrido, J.; Marques, M.P.M. Phenolic esters with potential anticancer activity - the structural variable. J. Mol. Model., 2007, 13, 865-877.

[35] Arora, S.K.; Germain, G.; Declercq, J.P. The crystal and molecular structure of lithocholic acid. Acta Crystallogr., 1976, B32, 415-419.

[36] Lamcharfi, E.; Cohen-Solal, C.; Parquet, M.; Lutton, C.; Dupré, J. Meyer, C. Determination of molecular associations of some hydrophobic and hydrophilic bile acids by infrared and raman spectroscopy. Eur. Biophys. J., 1997, 25, 285-291.

[37] Lamcharfi, E.; Meyer, C.; Lutton, C. Rationalization of the relative hydrophobicity of some common bile acids by infrared and raman spectroscopy. Biospectroscopy, 1997, 3, 393-401.

[38] Fiuza, S.M.; Van Besien, E.; Milhazes, N.; Borges, F.; Marques, M.P.M. Phenolic acid derivatives with potential anticancer properties - a structure-activity relationship study. part 1: methyl, propyl and octyl esters of caffeic and gallic acids. Bioorg. Med. Chem., 2004, 12, 3581-3589. 